\title{
Edible Plants of Saskatchewan
}

By Keith Best and Archie Budd, Swift Current, Saskatchewan

Although the staple food of the Saskatchewan Indian was buffalo meat, he also obtained much food from the native vegetation. The breaking up of the prairie sod, with the spread of settlement, has reduced, and in some cases almost eliminated, many of the edible plants, even though it has meant a great increase in the food stocks of the world. It must be borne in mind though that the plants relished by the Indian would not, of necessity, be palatable to us, as we have become used to less natural foods. Also "hunger is a good sauce" and the natural outdoor life of the plains Indian would make this sauce anything but scarce.

We will commence this series of articles on edible plants by describing some plants with palatable roots.

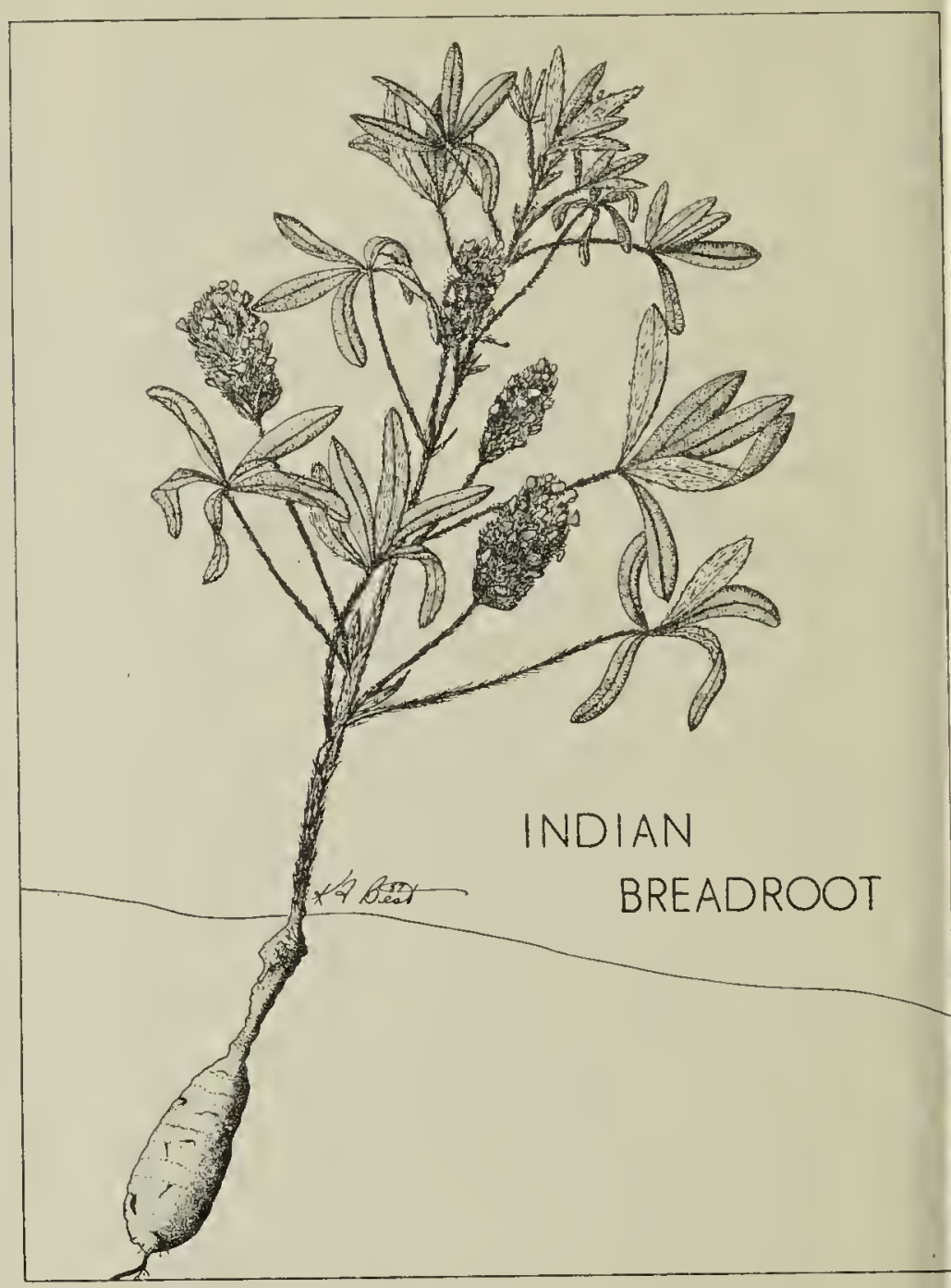

Perhaps the best known o the edible roots is the In dian Bread-root, (Psoraled esculenta) a plant of the Leguminosae or Pea family. This stubby little plan grows from 4 to 18 inche high and is densely clothe with loose white hairs. Thi leaves are palmate with fiv leaflets each from $3 / 4$ to inches long and the inflores cence is a dense oblong spik up to 2 inches high. The blu flowers are almost enclose in the hairy green sepals an therefore they are not ver conspicuous. The root long and slender but ends $i$ : a large, starchy tuber 0 cluster of tubers, generall from 6 to 10 inches belor the surface of the soil. A the squaws generally wer jo'ed for the digging it fortunate that this plant usually associated with th lighter or sandy soils. Th 


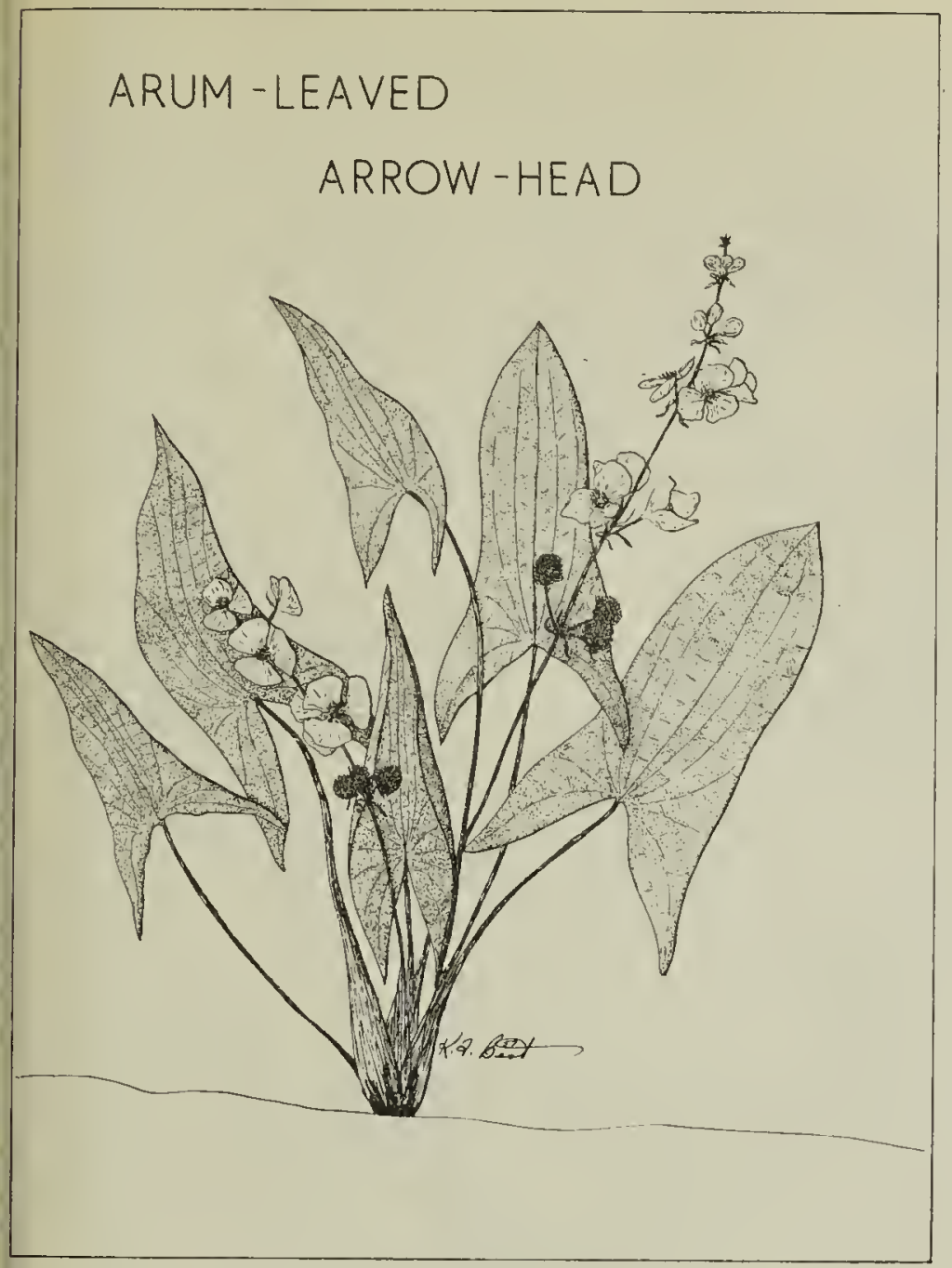

genera were dug up, roasted or baked, ground into flour and used for baking cakes. They were usually dug while the plant was in bloom.

Leaving the drier areas for the sloughs and water holes we find the Arrowheads, (Sagittaria cuneata), which bear palatable tubers and stem bases which, although somewhat bitter when raw, become quite pleasant tasting after boiling or roasting.

Nearby would probably be found the Cattails, (Typha latifolia), with their long, thick, creeping roots. The young roots and shoots and new stem bases were eaten by many of the Indians, raw according to some observers, but probably with less relish than the Bread-root and Biscuit-roots.

It is interesting to note that more than 25 species of plants with edible roots are still found in Saskatchewan.

roots were eaten either raw or cooked and often dried and ground into flour.

One of the earliest spring flowers is the Musineon, (Musineon divaricatum), a very low growing member of the Umbelliferae or Parsley family, which bears umbels of tiny yellow flowers and grows on eroded sidehills and dry soils throughout the southern part of the province. Very si milar plants are the Prairie Parsley or Biscuitroot of clay soils, (Lomatium villosa and L. macrocarpum), which differ from Musineon by being hairy on stems and leaves while Musineon is practically hairless. Plains Cymoperus, (Cymopteris acaulis), is another of the Umbellifers but differs from the previous two by having thinner leaflets and white flowers in somewhat larger $\mathrm{umbels}$. The roots of all these three

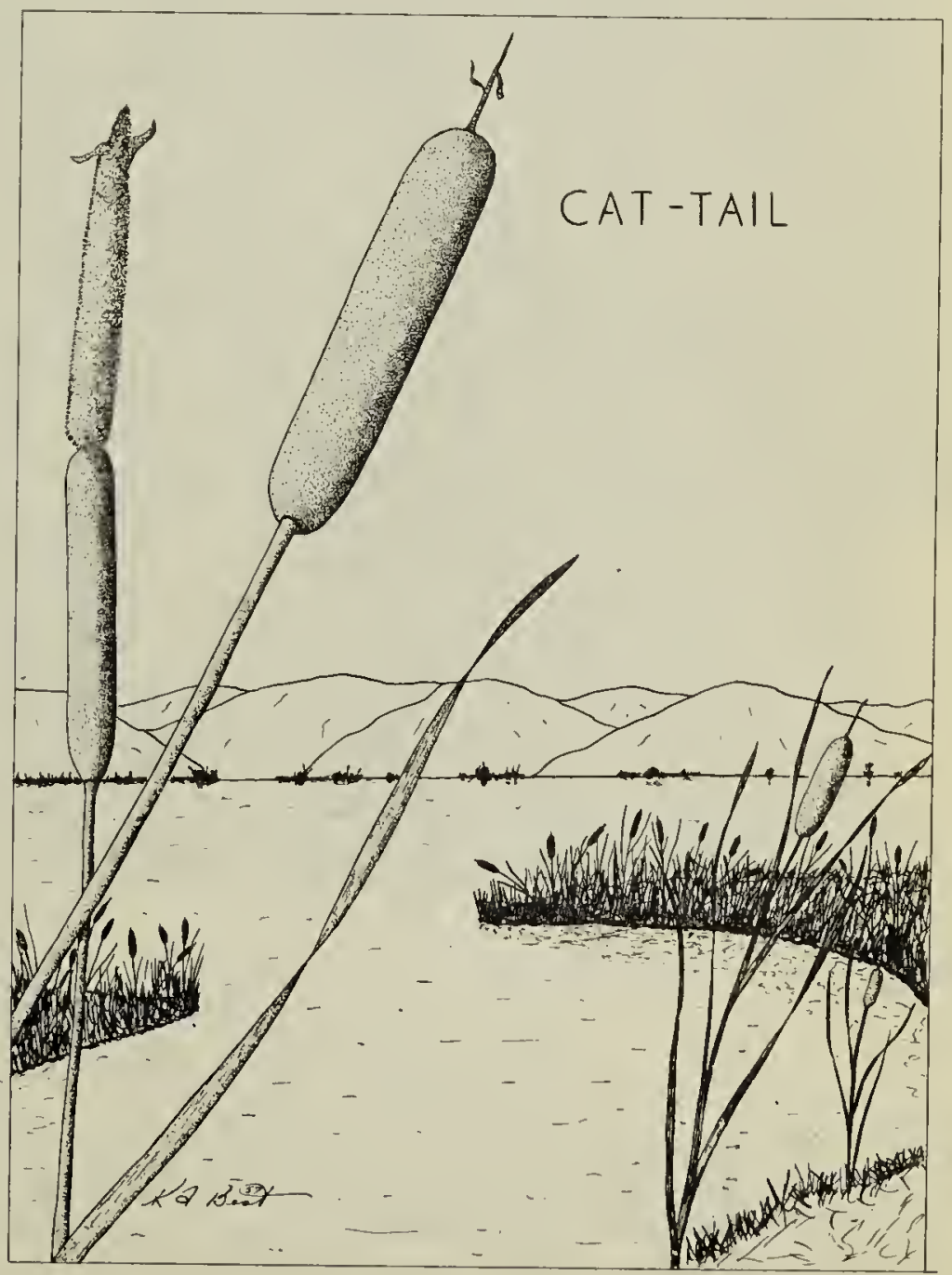




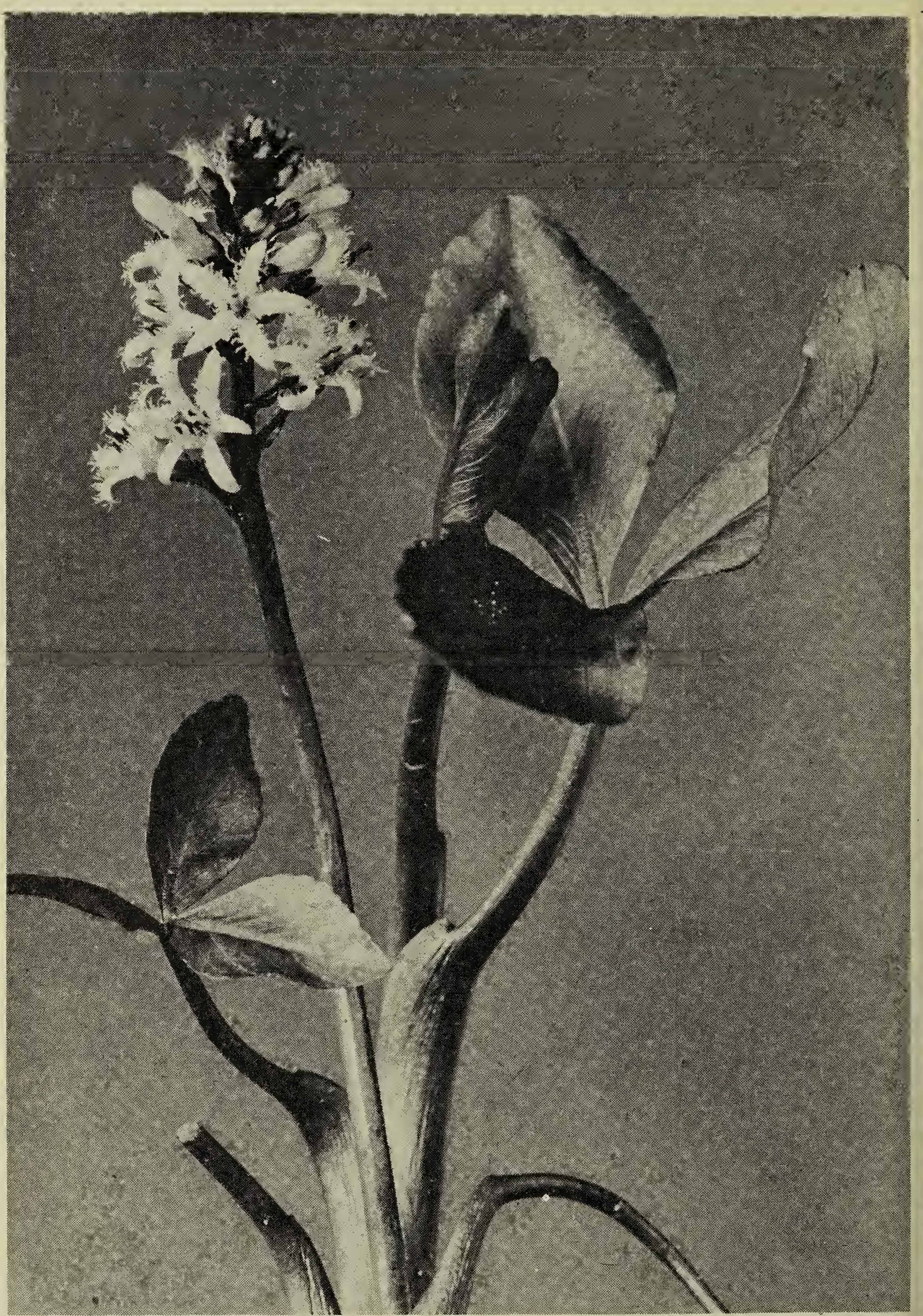

Photo by W. C. McCalla

\section{BUCK-BEAN}

Menyanthes trifoliata L. ( $2 / 3$ natural size)

An attractive bog or marsh plant. The flower buds are flushed with purple, the lobes of the corolla, white and soon reflexed, are softly anc prettily fringed. The Buck-bean should be coming into flower in the bogs around Emma Lake for our Summer Meeting, June 14 and 15, 1958. 